\title{
GCU
}

Glasgow Caledonian

University

University for the Common Good

\section{A Grounded theory study of the job-seeking experiences of foreign graduates on the German job market}

Kapanen, A.; Edgar, D.; Dressler, S.

Published in:

INTED2017 Proceedings

DOI:

10.21125/inted.2017.2237

Publication date:

2017

Document Version

Author accepted manuscript

Link to publication in ResearchOnline

Citation for published version (Harvard):

Kapanen, A, Edgar, D \& Dressler, S 2017, A Grounded theory study of the job-seeking experiences of foreign graduates on the German job market. in INTED2017 Proceedings. IATED, pp. 9474-9483, 11th International Technology, Education and Development Conference, Valencia, Spain, 6/03/17.

https://doi.org/10.21125/inted.2017.2237

\section{General rights}

Copyright and moral rights for the publications made accessible in the public portal are retained by the authors and/or other copyright owners and it is a condition of accessing publications that users recognise and abide by the legal requirements associated with these rights.

Take down policy

If you believe that this document breaches copyright please view our takedown policy at https://edshare.gcu.ac.uk/id/eprint/5179 for details of how to contact us. 


\title{
A GROUNDED THEORY STUDY OF THE JOB-SEEKING EXPERIENCES OF FOREIGN GRADUATES ON THE GERMAN JOB MARKET
}

\author{
A. Kapanen ${ }^{1}$, D. Edgar ${ }^{2}$, S. Dressler ${ }^{1}$ \\ ${ }^{1}$ HTW Berlin (GERMANY) \\ ${ }^{2}$ Glasgow Caledonian University (UNITED KINGDOM)
}

\begin{abstract}
This paper investigates foreign graduates' job-seeking experiences on the German job market. In order to explore the determinants of job-seeking success, it applies the Grounded Theory methodology. Based on seven in-depth interviews, it discovers 13 concepts linked to job-seeking and organises them into three thematic categories: preconditions for employment, perception of the labour market and strategies for job acquisition. Through discussion based on data and literature, the paper organises the categories into a process. On the basis of the process, a substantive Grounded Theory of achieving labour market success is presented.
\end{abstract}

Keywords: Employability, graduate labour market, international education, Germany, Grounded Theory

\section{INTRODUCTION}

Since several years, there is a growing shortage of qualified employees on the German labour market, especially in technical fields such as engineering and information technology. Therefore, there is a growing economic urgency to attract and retain qualified employees from abroad to meet employers' demand [1]. A promising channel for such migration is through the German higher education system; foreign university graduates plan an increasingly important role on the German labour market. The number of students at German universities with foreign entrance qualifications reached 320.000 in $2015,12 \%$ of all registered students, with $20 \%$ in the first semester [2]. While the number of foreign students is expected to grow, the current priority is to retain foreign graduates in Germany and facilitate their access to the labour market.

In addition to addressing general demand on the labour market, foreign graduates may be a valuable asset to German companies operating abroad. With over $50 \%$ of German companies doing business abroad and further expansion opportunities residing mainly outside the EU, foreign graduates can facilitate effective connections to international suppliers and markets, especially with large employers, who view the potential deployment of foreign graduates over native graduates [3] a distinct advantage in international business.

Regardless of the apparent demand, the employability of foreign graduates, in particular third-country citizens, have remained unsatisfactory. While surveys indicate that $80 \%$ of foreign students wish to work in Germany after graduation, only $25 \%$ or less succeed in finding full-time employment [4] [5]. Possible reasons for this have been studied to some extent and focus around insufficient German language skills; deficient knowledge of the German labour market and business context; insufficient career skills and weak career identity; recruiter reservations especially concerning long-term commitment; and time pressure resulting from residence permit limitations for foreign job-seekers [3] [5] [6]. Nevertheless, existing studies provide little insight into the actual job-seeking experiences of foreign graduates in Germany.

In particular, this research gap affects educators of foreign students at German universities who may not have a sufficient research base to effectively prepare foreign students for labour market entry. This paper aims at alleviating this gap by providing an empirical perspective to foreign graduates' jobseeking experiences on the German labour market. The term 'foreign graduate' is defined as a graduate of a German university who acquired his/her university entrance qualifications abroad and has a mother tongue other than German. The scope of job-seeking includes the search for suitable positions, as well as all formal and informal communication with an employer aiming at acquiring one such position. Drawing upon the insights of foreign graduates who have recently sought and gained employment, the paper develops Grounded Theory of the job-seeking process and the factors that determine job-seeking success. Section 2 describes the Grounded Theory methodology. Section 3 
introduces the findings and presents the analysis of the data and the construction of the Grounded Theory. Finally, section 4 concludes on the study and proposes further research.

\section{METHODOLOGY}

This study constructs Grounded Theory following the methodology described by Corbin and Strauss [7]. Originating from sociology, Grounded Theory has been applied to investigate complex social phenomena in a variety of fields. Grounded Theory is different from traditional survey methods and qualitative data analysis in that data is generated and analysed throughout the research journey. Through purposeful sampling, the researcher can discover new concepts and explore existing concepts further, improving the exploratory depth of the research. Grounded Theory can also be compared to the case study method as both utilise rich data from a variety of sources. Whereas case studies investigate phenomena in their real-life contexts and rely on theory for generalisation, Grounded Theory systematically discovers conceptual patterns in data in order to develop new theory that can explain or predict phenomena. In the field of employment, Grounded Theory studies have been conducted about recruitment and retention [8] and job satisfaction [9] among some other topics. However, in employability research, Grounded Theory remains untypical and therefore this paper explores its potential of broadening the methodological boundaries in the field. The Grounded Theory principles followed in this study are summarised in Table 1 and discussed below.

Table 1. Overview of Grounded Theory principles as applied in this study

\begin{tabular}{|c|l|}
\hline Principle / method & Description \\
\hline Role of the researchers & $\begin{array}{l}\text { Interactive data generation with participants; interpretation of data utilises } \\
\text { researcher experience and expertise. }\end{array}$ \\
\hline Pragmatism & $\begin{array}{l}\text { A research paradigm aimed at improving the real existing circumstances } \\
\text { of foreign graduate employability in Germany. }\end{array}$ \\
\hline Theoretical sampling & $\begin{array}{l}\text { Purposeful sampling of participants on the basis of what concepts } \\
\text { require further development at each research stage. }\end{array}$ \\
\hline Abductive reasoning & $\begin{array}{l}\text { Logic of making discoveries in data in an ordered way; iterates between } \\
\text { data generation and analysis. }\end{array}$ \\
\hline In-depth interviews & $\begin{array}{l}\text { The practice of interviewing with minimal predetermined structure, } \\
\text { following up on themes as they emerge. }\end{array}$ \\
\hline Analytical strategies & $\begin{array}{l}\text { Grounded Theory analysis procedures. Coding refers to denoting } \\
\text { concepts in data on three levels of abstraction (open, axial and } \\
\text { theoretical coding). Memoing is the analytical activity of writing the } \\
\text { thought processes. }\end{array}$ \\
\hline Theoretical saturation & $\begin{array}{l}\text { Determine procedures for identifying concepts among the data and } \\
\text { assigning meaning to them. }\end{array}$ \\
\hline Use of literature & $\begin{array}{l}\text { The point in the research process when all concepts in the Grounded } \\
\text { Theory have been sufficiently developed and no more significant } \\
\text { concepts seem to emerge. }\end{array}$ \\
\hline Substantive Grounded \\
Theory & $\begin{array}{l}\text { Literature is used after data generation and analysis to contextualise and } \\
\text { discuss the findings. }\end{array}$ \\
\hline $\begin{array}{l}\text { Theory tied to existing practical circumstances through the Grounded } \\
\text { Theory process. }\end{array}$ \\
\hline
\end{tabular}

Grounded Theory is about 'discovering new meanings in the social world' [11]. In this research, Grounded Theory is applied to explore factors that may influence the job-seeking success of foreign graduates and thus provide insights into a previously insufficiently understood phenomenon. The Grounded Theory of Corbin and Strauss ([7] p. 18-19) is anchored in the philosophy of pragmatism, in which ideas refer to possibilities to act and 'knowledge arises through ... acting and interacting of selfreflective beings'. As the authors are international higher education practitioners, they have an inherent professional interest in enhancing foreign graduate employability; as well as previous experience in related educational practices. As 'there is not just one theory that can be developed from data' ([7] p. 53), the researchers' worldview, knowledge and experiences necessarily affect the research outcome. Therefore, the outcome of the research is substantive theory, which is pragmatic theory tied to the researchers' empirical area ([10] p. 33). While lacking universal implications, the substantive theory can support practitioners in designing educational interventions for improving foreign graduate employability. 
In order to anchor the research in the reality of foreign graduate jobs-seekers, participants with diverse job market experiences were sampled. A good sample in Grounded Theory research is sufficiently diverse to cover variations in people's perceptions within the specific research question [11]. The driving principles of Grounded Theory are abduction and theoretical sampling ([7] p. 135; [12] p. 225), where abduction refers to a way of reasoning that seeks 'new discoveries in a logically and methodologically ordered way' ([12] p. 216) and theoretical sampling reflects purposeful sample techniques. In this analysis, the abductive process oscillated between data generation (foreign graduate interviews) and data analysis (coding and memoing) with each iteration generating new data. For theoretical sampling, a selection of participants believed to yield data useful at that stage of the research were targeted. Potential participants were sought through email and postings on social media. The progress of theoretical sampling is presented in Table 2. After the seventh interview, it was judged that sufficient data for constructing the theory exists. As no new concepts emerged, a reasonable level of theoretical saturation had been reached.

Table 2. Overview of the participants and the theoretical sampling

\begin{tabular}{|c|l|}
\hline Participant \# & Short description \\
\hline P1 & $\begin{array}{l}\text { South Asian graduate with background in Information Technology and a } \\
\text { subsequent Master in Business Administration from Germany. Three years of } \\
\text { experience as IT manager at an international services company in Hessen. } \\
\text { Sampled for: Gaining initial data }\end{array}$ \\
\hline P2 & $\begin{array}{l}\text { East European graduate with background in architecture and a subsequent } \\
\text { Master in Urban Studies from Germany. Two years of experience as project } \\
\text { manager at a consultancy in Brandenburg. } \\
\text { Sampled for: Broadening the scope of job market perceptions }\end{array}$ \\
\hline P3 & $\begin{array}{l}\text { Central Asian graduate with background in marketing and a subsequent MBA } \\
\text { from Germany. Recently began as a project employee at an SME in Saxony. } \\
\text { Sampled for: Insight into the transition from studies to employment }\end{array}$ \\
\hline P4 & $\begin{array}{l}\text { Southeast Asian graduate with background in manufacturing and a subsequent } \\
\text { Master in industrial engineering degree from Germany. Three years of experience } \\
\text { as technical expert at a semiconductor company in Saxony. } \\
\text { Sampled for: Gaining insight into success factors }\end{array}$ \\
\hline P5 & $\begin{array}{l}\text { South Asian graduate with background in engineering and a subsequent Master in } \\
\text { industrial engineering from Germany. Four years of experience at an energy } \\
\text { company in Baden-Wuerttemberg. } \\
\text { Sampled for: Gaining insight into success factors }\end{array}$ \\
\hline P6 & $\begin{array}{l}\text { East European graduate with business administration background and a } \\
\text { subsequent international business degree from Germany. One year of experience } \\
\text { as a marketing manager at an internet company in Berlin. } \\
\text { Sampled for: Adding variability to job-seeking experiences }\end{array}$ \\
\hline P7 & $\begin{array}{l}\text { South European late-stage student in a business administration Master } \\
\text { programme in Berlin. Currently looking for employment in Germany. } \\
\text { Sampled for: Insight into initial challenges of job-seeking }\end{array}$ \\
\hline
\end{tabular}

In-depth interviews were selected as the method for exploring the participant perceptions without forcing the answers to fit a predetermined structure. The interviews were conducted per Skype in informal settings. The first participant (P1) was prompted to tell about his job-seeking experiences; further prompts following up on the themes brought up by the participant. Further participants were given a similar initial prompt, followed by prompts related to the concepts discovered so far.

The analysis procedures of coding and memoing were conducted manually. Coding is the process of 'going through data and denoting concepts to stand for that data' ([7] p. 58) where coding took place on different levels of abstraction from denoting low-level concepts among the data and grouping them to categories (open coding); to discovering high-level relationships between the codes and categories (axial coding). The axial coding was the basis for integrating the theory presented in Fig. 1. The details of the analytical thought process of moving from low-level concepts to theory were recorded in a series of analytical memos. An overview of the concepts and categories discovered among the data is given in Table 3. The subsequent discussion in section 3 draws on the analytical memos. The analytical strategies applied in the memoing were adapted from Corbin and Strauss ([7] pp. 90-101) and included mainly questioning the data, making comparisons between incidents of concepts and making use of experience to interpret data. Empirical literature was included toward the research process in order to contextualise the findings. 


\section{FINDINGS AND GROUNDED THEORY CONSTRUCTION}

Seven participants were interviewed within the study, as presented in Table 2. The Grounded Theory process began by generating initial data with $\mathrm{P} 1$, a recent graduate who started seeking employment nearing the end of his studies and gathered diverse job-seeking experiences before finding a position that matches his qualifications. After analysing the initial data, participants P2 - P7 were sampled progressively for the reasons given in Table 2. The concepts emerged from the open coding of interview transcripts and were organised into categories, which were developed and refined throughout the Grounded Theory process. The codes and the categories are summarised in Table 3 , where the columns P1 - P7 give the number of incidences of each concept in each interview transcript. The concepts and categories are discussed in sections $3.1-3.3$ and the theory integrated in section 3.4.

Table 3. Summary of the concepts and categories discovered among the data

\begin{tabular}{|c|c|c|c|c|c|c|c|c|}
\hline Categories & Codes & P1 & $\mathbf{P 2}$ & P3 & $\mathbf{P 4}$ & P5 & P6 & P7 \\
\hline \multirow{4}{*}{ 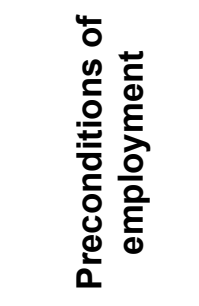 } & Desire to stay and work in Germany & 0 & 1 & 1 & 1 & 0 & 3 & 1 \\
\hline & Understanding the German context & 0 & 0 & 1 & 3 & 3 & 1 & 1 \\
\hline & Knowing languages & 3 & 1 & 1 & 1 & 2 & 4 & 5 \\
\hline & Developing a career identity & 2 & 2 & 3 & 1 & 1 & 2 & 1 \\
\hline \multirow{3}{*}{ 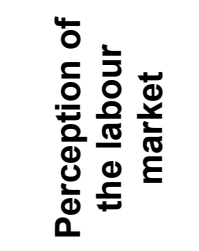 } & Setting realistic goals & 0 & 1 & 0 & 2 & 2 & 1 & 2 \\
\hline & Discovering job options & 2 & 2 & 1 & 0 & 0 & 2 & 1 \\
\hline & Sustaining motivation to apply & 2 & 1 & 0 & 0 & 1 & 2 & 2 \\
\hline \multirow{6}{*}{ 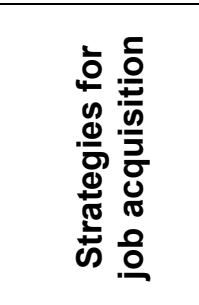 } & Planning and managing applications & 1 & 5 & 1 & 0 & 1 & 1 & 0 \\
\hline & Addressing employer expectations & 2 & 1 & 0 & 2 & 5 & 5 & 1 \\
\hline & Using international background & 3 & 4 & 0 & 0 & 3 & 0 & 2 \\
\hline & Gaining support from university & 0 & 1 & 0 & 1 & 2 & 1 & 1 \\
\hline & Using personal references & 2 & 0 & 2 & 2 & 3 & 0 & 0 \\
\hline & Negotiating job offers & 0 & 2 & 0 & 0 & 0 & 2 & 1 \\
\hline
\end{tabular}

\subsection{Preconditions of employment}

Successful job-seeking as foreign graduate in Germany depends on fulfilling a number of personal preconditions. 'Desire to stay and work in Germany' describes the participants' fundamental motivations for establishing a life in Germany. P2 and P6 could speak fluent German and therefore had a connection to the German culture before arriving; both were genuinely interested in the experience of living in Germany, in particular. P3 also had connections to Germany through her former employment, which motivated her to move. In contrast, P4 and P7 had no previous personal connection with Germany but were motivated to move because of expectations regarding the lifestyle (P4) and job market (P7), which they perceived to be more attractive than those at home. Hanganu and Hess ([4] p. 218) found the most important motivation factors for academic migration to Germany to include the desire to gain international experience (very important or important to $80 \%$ of respondents), followed by private reasons and perceived poor career and life prospects at home. Their findings resonate with this study. While the generic desire to gain international experience was less emphasised, both private and professional reasons were given by the participants as important reasons to stay. Demonstrable desire to stay on long term may be an employment factor: The Stifterverband [3] found employers to value foreign graduates' long-term commitment. Previous connections to Germany, as discussed by P2, P3 and P6, may promote long-term commitment as they give a more realistic picture of the country at the time of migration. This may also promote acculturation and integration, which are important success factors in migrants' careers [13]. P3 and P4 discussed the need to immerse in the German society in order to decide whether they want to stay in 
long term. Kapanen et al. [14] suggest that study-related internships contribute significantly to foreign student employability and may have a similar impact on acculturation, as well.

'Understanding the context' describes whether a foreign graduate has sufficient understanding of the German context of employment. Legal, cultural and labour market aspects were identified among the data. The concept emerged in interview P3 and was followed up in interviews P4 and P5. P4 focused on the German workplace context. He suggested that understanding the German conditions of employment, which were different to his home country, improved his self-confidence and collaboration with colleagues. P5 stressed the importance of understanding the German labour market, especially recruitment norms. Coming from a country with a talent-oriented labour market, P5 had difficulties coping with the strong focus on occupation and formal occupational qualifications in Germany. P6 added that in her experience, third-country students often did not have good understanding of the legal conditions, such as working permit requirement and tax formalities. The least experienced participant, P7, recognised that she lacked even basic knowledge of the German labour market. Deficient knowledge of the labour market has been recognised as a key hurdle to foreign graduate employability [5]. Lokhande [5] proposes voluntary engagement and internships during the studies as means to improve contextual understanding, in particular because they provide a diversity of experiences and connections to persons with expertise and willingness to help at the early career stages. These findings are confirmed by Alichniewicz and Geis [15], who additionally conclude migration via higher education to provide better career chances than other forms of migration.

'Knowing languages' refers to language skills as determinants of job-seeking success. Language was an overarching theme in the interviews and all participants pointed at the challenge of using German at work. P1 discussed the time required to learn German and observed that initial skills gained in language classes are hardly useful in job-seeking without lengthy practice in real life contexts. As an early-stage job-seeker, P7 perceived most entry-level positions to require a level of German beyond typical foreign graduates. P5 and P2 saw their international experience, language skills and cultural versatility to give a job-seeking advantage. Other studies suggest poor language skills to be a decisive hurdle to labour market access [5]. However, while large employers agree that German skills are a hurdle, they acknowledge foreign graduates' greater potential for international business [3]. Especially students joining the growing number of English spoken degree programmes offered in Germany need ways to develop their language skills in order to improve their job-seeking success.

Finally, 'developing a career profile' refers to how graduates perceive themselves and offer their capabilities on the labour market. The analysis indicated that several years of experience are required to develop clarity of the career profile. The least experienced participants showed uncertainty about their career choices. The inexperienced late-stage business student, P7, discussed her interests but could not describe a strategy for matching her profile with any position. P3, a recent graduate with prior work experience, saw the studies in Germany as career 'crossroads', which she intended to use to embark on a new career but also lacked a clear profile to offer. In contrast, the more experienced participants P1, P4 and P5 could easily describe their labour market position. In addition to their experience, these participants have technical education that more easily agrees with the German occupationally oriented labour market and addresses an existing gap in labour supply [2].

The 'preconditions of employment' arise as a result of learning and self-reflection, which typically begin well before a person joins the host university in Germany and continues after his or her graduation. In addition to facilitating learning and self-reflection opportunities for example in the form of seminars, workshops and advisory, universities are advised extend their reach beyond the duration of the studies. For example, an online self-assessment may provide a useful instrument to help candidates understand what knowledge, skills and attitudes they are likely to need to find employment in Germany; and give several additional months to prepare respectively. Personal advisory may help recent graduates reflect upon their motivations and preconditions for continued career in Germany.

\subsection{Perception of the labour market}

The second category comprises the perceptions of foreign graduates regarding their future employment. It determines the principles that guide the daily job-seeking activities of foreign graduates. The most abstract code in this category is 'setting realistic goals'. It refers to what a graduate believes to be realistic expectations concerning job characteristics such as title, income, responsibility and power. P1, P4 and P5 had identified their realistic goals by reflecting upon what tasks their technical skills and experience allow them to carry out. These experienced participants, who linked their goal-setting to clear occupational profiles, reported having achieved their goals. P2 explained that because she had completed a degree focusing on a narrow specialist field, she could 
easily set realistic goals at graduation. In contrast, $\mathrm{P} 7$, who had completed a general business degree and had little prior experience, had difficulties setting employment goals at all. The findings are in line with the observation of Greenhaus et al. [16] that realistic goal-setting depends on a sufficient career exploration, which allows individuals to "enhance their awareness of themselves (values, interests, talents, and preferred lifestyle) and their environment (occupations, jobs, career paths, organizations, industries, and family constraints).' The term career exploration involves not only gathering information on the self and the environment but also reflecting upon it to 'aid the development and implementation of appropriate career strategies or action plans' [16].

By 'discovering job options', graduates explore the available job opportunities and their requirements in order to decide upon what kind of positions to apply to. The participant insights revealed some techniques for job search and evaluation. P1, P3 and P6 reported using job portals, company websites and social media for identifying positions. Overall, the participants had paid little attention to exploring the German job market. Not only was there little indication of systematic job market exploration, the applied techniques were very limited. Notably, none of the participants reported using business directories or databases, visiting trade fairs, contacting trade associations or communicating with employers directly to explore the job market. The findings coincide with broader surveys, which reveal foreign job-seekers to suffer commonly of weak labour market understanding and at the same time insufficient career advisory services [17].

Finally, 'sustaining motivation to apply' refers to a graduate's ability to overcome the frustration caused by rejections and keep applying, and learning application skills, until suitable employment is found. Graduates typically send tens of applications in order to gain employment [6]. Some participants reported unhelpful behaviour by employers, which they perceived as demotivating. P1 and P2 reported often receiving no response to applications and experiencing excessive waiting times after interviews; P5 perceived many employers unwilling to provide information and discuss possible job options; and P6 felt frustrated by complicated or dysfunctional online application platforms. Such observations coincide with previous studies [17]. Strategies to sustain motivation were identified, as well. P2 reported employer response to improve significantly as her applications grew more targeted and specific to each position. Along the same line, P5 suggested continuously reflecting upon and improving job applications to sustain motivation. Finally, P6 began applying well before graduation and indicated good scheduling of applications to reduce the period of uncertainty between graduation and the next employment.

In summary, 'perception of the labour market' arise from individual learning and self-reflection. While universities may develop detailed qualification profiles for specific degree programmes, foreign students arrive to Germany with varying prior education, experience and motivations. Therefore, universal profiles may not be as useful as intended and a more useful strategy may be to facilitate individual career evaluation and reflection opportunities before, during and after the studies. Also opportunities for career exploration through real-life experiences like internships and volunteering are important. Linking career advisory more intensely to the academic guidance of such activities may help foreign students benefit more of them. Using web resources such as those provided by the DAAD and the Make it in Germany portal, such guidance does not necessarily require high additional workload by the academic. Without fulfilling the preconditions and setting realistic expectations for employment, even appropriate strategies for job application may not yield the expected results.

\subsection{Strategies for job acquisition}

The successful acquisition of job positions requires strategies that utilise the graduates' available labour market assets, including job application skills, understanding of employer expectations and strategies to address them, and social resources. The first code, 'planning and managing applications', concerns to job application skills and describes the participants' ability to manage the job application process. P2 described her learning process, moving from ad-hoc to planned and managed applying. By increasing the time spent applying, her applications became more targeted and coordinated, which yielded her more interviews than before and avoided problems such as applying to a company twice without noticing. P1 discussed balancing the available time between opportunities; as writing custom applications took significant time, focusing the most attractive opportunities was essential. However, the smaller the number of applications sent, the more success may depend on setting realistic goals and discovering the matching opportunities. P6 demonstrated the importance of beginning early. By applying during her last semester at university, she obtained a job by graduation. None of the participants demonstrated a systematically managed and reflective job application process that would make use of a database of found opportunities and sent applications, scheduled 
follow-up calls or a journal to record experiences. Kapanen et al. [18] observed that universities may not comprehensively provide such skills and it often rests on the individual to acquire them [18].

'Addressing employer expectations' relates to the content and presentation of job applications with respect to perceived employer expectations. P2, P4 and P5 pointed out importance of detailing how the candidate's education, experience and other attributes match the employer's requirements. P4 and P5 observed the focus to lie on the occupational profile rather than personality of generic skills. According to P5, German employers typically 'want to take somebody who suits them $100 \%$, what else they don't care, even if the person is extraordinary genius.' He also emphasised the importance of self-awareness and effective presentation, observing that 'you need to know how the other person responds to a CV in 30 seconds' and in order to impress them, 'to know what my strengths are, what my weaknesses are and ... which jobs I have to apply rather than just apply the next 100 job postings available on the internet.' This links 'addressing employer expectations' to both concepts of selfawareness and environmental awareness suggested by Greenhaus et al. [16].

International competency may provide another argument to address employer expectations. The code 'using international background' refers to graduates pursuing opportunities where their native culture and language skills are advantageous. In her initial contact with the German labour market, P7 used her native community to gain an internship where she could use her native language. For $\mathrm{P} 1$, his native background was a recruitment factor as he acts as a contact to a service provider in his home country. P5 stated that his international experience was likely the most important recruitment factor. While international experience often contributes to employability [3] [14] [16], it may only do so when combined with German language skills and contextual understanding (as discussed in section 3.1). Such conditions may also not be obvious in job ads and identifying them may require significant effort by the candidate.

'Gaining support from university' refers to making use of the various types of career support offered by universities. Various types of support may be available not only centrally from career services but also locally from academics and student organisations. Due to recent increasing attention to the university as a channel of migration to the German labour market, universities have accelerated the development of effective support practices [19]. However, support offerings are still considered insufficient to effectively enhance foreign graduate employability [5]. While some participants (P2, P3, P6) had gained concrete career support from their universities, others (P1, P5) stated explicit dissatisfaction with the support offerings. Based on the authors' experience, workshops and materials alone are typically insufficient and personal advisory is needed to improve foreign students' job acquisition strategies.

'Using personal references' was one of the most prevalent codes among the data. The participants seemed to count strongly on personal references in job search; and provided justification among the data. P5 perceived a significantly better employer response to applications involving a personal reference. He also pointed out that references are only effective when the candidate is able to use them for example to gain information or access to decision-makers. P4, who found his current position through a previous professional contact, occasionally gains job offers from other employers within his professional network, helping him maintain opportunity awareness.

Finally, by 'negotiating job offers', the candidate and the employer come to agreement about the terms of employment. P2 and P6 observed that their success in negotiating job offers depended on their understanding of the context and typical conditions of employment in the given field. They also suggested that having more than one job option to choose from improved their confidence and position in the negotiations. $\mathrm{P} 2$, who had participated the most job interviews among the sample, reported her interviewing skills to have improved rapidly with successive job interviews, yielding better results and improving her confidence toward the end. These findings suggest that it may not be in the interest of foreign graduates to accept the first available position at any conditions but instead improve their negotiation skills and compare offers to acquire a more suitable initial position.

Some of the job acquisition strategies that emerged from the data as such that can be taught at universities. For example, techniques for application planning and management, as well as creating job application documents, can be effectively learnt independently, in classroom or online. Other strategies, however, are enabled by individual learning and self-reflection. These 'behind-the-scenes' strategies, that include building personal networks and exploring subtle career opportunities, require a range of personal attributes such as proactive behaviour, curiosity and research skills. Therefore, in order to genuinely improve foreign graduates' job acquisition strategies, universities may be advised 
holistic strategies that encompass student recruitment, education, extracurricular activities, advisory and alumni work.

\subsection{Integration and discussion of the Grounded Theory}

The previous sections $3.1-3.3$ discussed the concepts and categories that emerged from the data. This section integrates the categories into an initial Grounded Theory of foreign graduate job-seeking in Germany. The elements of the theory and their relationships are visualised in Fig. 1.

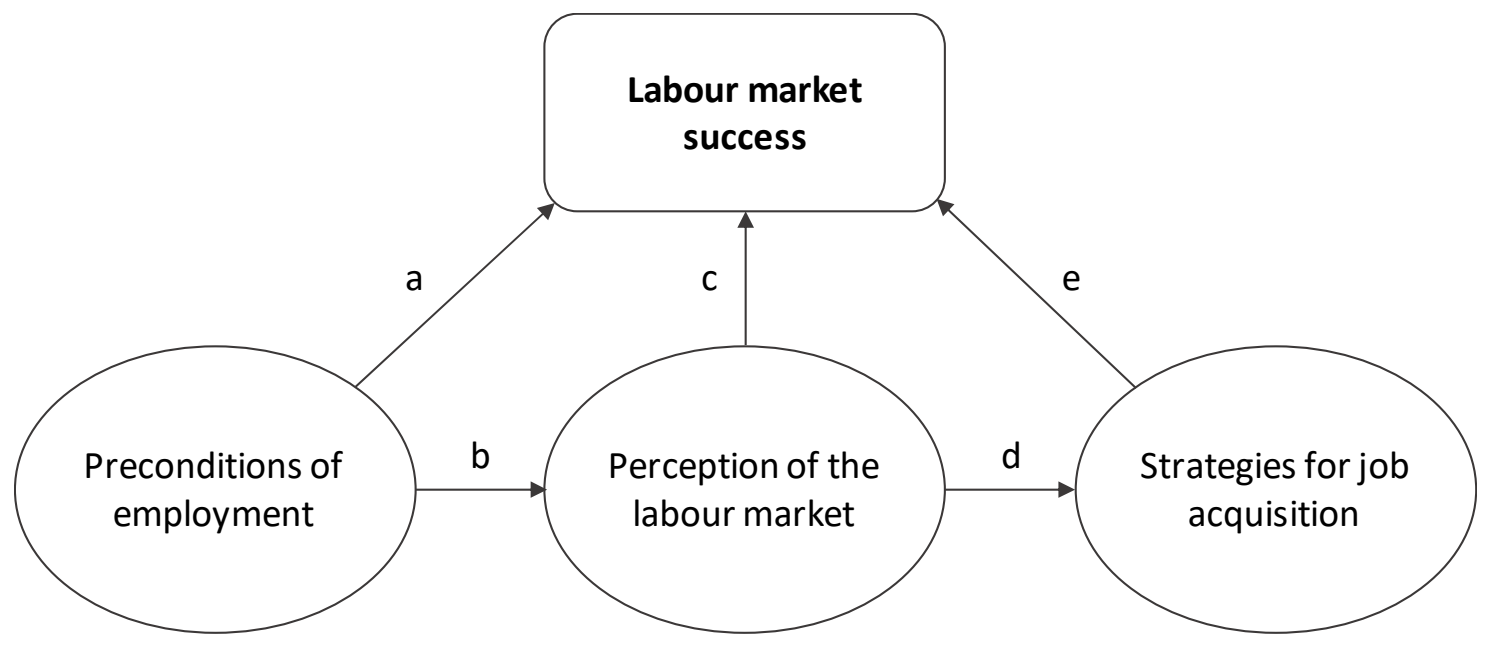

Fig. 1. Visualisation of the initial Grounded Theory

In line with the pragmatist agenda of the research, the initial problem of labour market success of foreign graduates was chosen as the central element of the theory. The determinants of labour market success lie in the three previously developed categories, which are mutually dependent. Therefore, the Grounded Theory empirically connects between foreign graduate attributes and activities, and labour market success. The elements of the theory are explained below.

Without a sufficient motivation to stay in Germany, ability to communicate with others and understanding of the socioeconomic context, the chances of labour market success are drastically reduced. On the one hand, graduates not fulfilling these preconditions may lack the ability to work effectively in the given context (a); on the other hand, they may not be able to identify suitable, realistic employment opportunities (b). Graduates who fulfil the basic preconditions can progress to developing a perception of the labour market. Through an exploration of the self and the environment, they are able to set career goals, identify concrete opportunities to match those goals, and summon and sustain the motivation to pursue them. Graduates with unrealistic goals may not find positive reactions from employers (c); and graduates unable to identify suitable opportunities or sustain motivation to apply may not be able to develop and carry out effective strategies for job acquisition (d). Finally, graduates with a realistic perception of the labour market are in position to develop the most effective strategies for acquiring a suitable position. Without adequate job acquisition skills and resources, graduates may not be able to turn opportunities into acceptable job offers (e).

As discussed in section 3 , the theory suggests labour market success to depend on knowledge and skills that can be taught and learned at university, as well as personal qualities and preferences that arise from proactive exploration and self-reflection. Furthermore, while skills such as job application techniques can be taught in a reasonably short time, others such as context-specific communication skills typically take years to learn. Therefore, the theory points at the need for German universities to establish holistic support models that help foreign students to assess as early as possible before the studies to what extent they fulfil the preconditions for employment; to set realistic goals and develop a career vision; and acquire the knowledge, skills and other attributes required for effectively pursuing labour market success.

\section{CONCLUSIONS AND FURTHER WORK}

This paper set out to investigate the job-seeking experiences of foreign graduates on the German job market. The investigation was conducted using a Grounded Theory methodology, drawing upon indepth interviews with seven participants. The Grounded Theory, presented in Fig. 1, comprises 13 
concepts organised in three categories. These are 'preconditions of employment' without which effective action is unlikely; 'perception of the labour market' describing the results graduates expect of job-seeking; and 'strategies for job acquisition' that guide the activities of searching and applying for jobs. Linked together, these categories constitute a substantive Grounded Theory of how the jobseeking process contributes to graduate employability. The Grounded Theory and the discussion offered in this paper may contribute to the effective preparation of foreign students for post-graduation for job search in Germany. It provides a basis for both individual self-reflection and the design of support practices at the host universities. Applied to practice, the theory may make a contribution to addressing the problem of deficient labour market outcomes described at the beginning of the paper.

The Grounded Theory methodology is uncommon in employability research and therefore this paper involved a degree of methodological exploration. On the basis of this study, the methodology is promising in investigating especially the complex social aspects of employability. Its pragmatist, substantive orientation links it closely real life problems, which its procedural foundation may help solve.

As this paper presented initial Grounded Theory, further research is necessary to evaluate its practical implications and refine it accordingly. While this paper drew upon a range of literature, further work to situate the theory among other theories of graduate employability may enhance its usefulness. Moreover, further research applying the Grounded Theory methodology to other factors of employability and other types of relevant stakeholders may contribute to a more complete understanding of foreign graduate employability in Germany.

\section{REFERENCES}

[1] VDI, "Ingenieurmonitor 2016/III. Der regionale Arbeitsmarkt in den Ingenieurberufen," Verein Deutscher Ingenieure (The Association of German Engineers), Duesseldorf, 2016, retrieved from https://www.vdi.de/fileadmin/user upload/Ingenieurmonitor 2016-Q3.pdf

[2] Federal Statistical Office (Germany) (2015). Bildung und Kultur. Studierende an Hochschulen, Wintersemester 2014/15. Fachserie 11, Reihe 4.1, 2015, Retrieved from https://www.destatis.de/DE/Publikationen/Thematisch/BildungForschungKultur/Hochschulen/Stu dierendeHochschulenEndg2110410157004.pdf? blob=publicationFile

[3] Stifterverband, "Hochschulbildungsreport 2020, Jahresbericht 2015, Schwerpunkt: Internationale Bildung," Stifterverband für die Deutsche Wissenschaft together with McKinsey \& Company, 2015, retrieved from http://www.hochschulbildungsreport2020.de/download/file/fid/40

[4] E. Hanganu and B. Hess, "Beschäftigung ausländischer Absolventen deutscher Hochschulen. Ergebnisse der BAMF-Absolventenstudie 2013," Federal Office for Migration and Refugees (Germany), Nuremberg, 2014, retrieved from http://www.bamf.de/SharedDocs/Anlagen/DE/Publikationen/Forschungsberichte/fb23hochschulabsolventen.pdf

[5] M. Lokhande, "Engagiert gewinnt. Bessere Berufschancen für internationale Studierende durch Praxiserfahrungen," SVR-Forschungsbereich, 2016, retrieved from https://www.svrmigration.de/wp-content/uploads/2016/02/Factsheet-internationale-Studierende.pdf

[6] A. Kapanen, D. Edgar and S. Dressler, "Self-perceived Development of Employability in International Postgraduate Business and Engineering Students in Germany," EDULEARN15 proceedings, 2015.

[7] J. Corbin and A. Strauss, "Basics of qualitative research. Techniques and procedures for developing grounded theory," 4th edition, SAGE Publications, London, 2015.

[8] J. Long, "Grounded theory: Its use in recruitment and retention," Journal of Management \& Marketing Research, Sep 2012, Vol. 11, 2012, retrieved from http://www.aabri.com/manuscripts/121202.pdf

[9] M. Izvercian, S. Potra and L. Ivascu, "Job Satisfaction Variables: A Grounded Theory Approach", Social and Behavioral Sciences 221 ( 2016 ) 86 - 94, 2016, doi: 10.1016/j.sbspro.2016.05.093

[10] B. Glaser and A. Strauss, "The discovery of grounded theory: Strategies for qualitative research," Aldine Publishing, Chicago, 1967. 
[11] A. Dourdouma and K. Moertl, "The creative journey of grounded theory analysis: A guide to its principles and applications," Research in Psychotherapy: Psychopathology, Process and Outcome 2012, Vol. 15, No. 2, 96-106, 2012, doi: 10.7411/RP.2012.010

[12] J. Reichertz, "Abduction: the logic of discovery of grounded theory," In: A. Bryant and K. Charmaz (eds.): The SAGE handbook of grounded theory, pp. 214-228, SAGE Publications, London, 2007.

[13] N. Tharmaseelan, K. Inkson and S. Carr, "Migration and career success: testing a time sequenced model," Career Development International, Vol. 15, Issue 3 pp. 218 - 238, 2010, doi: 10.1108/13620431011053712

[14] A. Kapanen, S. Dressler, D. Edgar and T. Rachfall, "Enhancing employability skills through internships: Perceptions of foreign Master students in Germany," ICERI16 proceedings, 2016.

[15] J. Alichniewicz and W. Geis, "Zuwanderung über die Hochschule," IW-Trends, Oct 2013, Retrieved from

http://www.iwkoeln.de/ storage/asset/130637/storage/master/file/7081392/download/Internation alisierung\%20d.\%20Bildung\%20Studie.pdf

[16] J. Greenhaus, G. Callanan and E. Kaplan, "The role of goal setting in career management," International Journal of Career Management, Vol. 7 Iss 5 pp. 3 - 12, 1995, retrieved from http://dx.doi.org/10.1108/09556219510093285

[17] S. Morris-Lange and F. Brands, "Zugangstor Hochschule: Internationale Studierende als Fachkräfte von morgen gewinnen," SVR-Forschungsbereichs, 2015, retrieved from http://www.svr-migration.de/publikationen/

[18] A. Kapanen, S. Dressler, D. Edgar, B. Temple, T. Rachfall and D. Foerster-Trallo, "Developing a MOOC for teaching employability skills to foreign students in Germany," EDULEARN16 proceedings, 2016.

[19] DAAD, "Ergebnisbericht zur Evaluierung des DAAD-Programms 'STIBET I und STIBET III Matching Funds'," German Academic Exchange Service, Bonn, 2014. 